\title{
Environmental Risk Trade-off for New Generation Vehicle Production: Malaysia Case
}

\author{
Muhammad Azmi ${ }^{1} \&$ Akihiro Tokai ${ }^{1}$ \\ ${ }^{1}$ Environmental Management, Division of Sustainable Energy and Environmental Engineering, Graduate School \\ of Engineering, Osaka University, Japan
}

Correspondence: Muhammad Azmi, Environmental Management, Division of Sustainable Energy and Environmental Engineering, Graduate School of Engineering, Osaka University, Japan. E-mail: muhammad@em.see.eng.osaka-u.ac.jp

Received: October 21, 2016 Accepted: November 24, 2016 Online Published: November 30, 2016

doi:10.5539/jsd.v9n6p132

URL: http://dx.doi.org/10.5539/jsd.v9n6p132

\begin{abstract}
New Generation Vehicle such as Hybrid Electric (HEV) and Battery Electric Vehicles (EV) have higher efficiency compared to conventional vehicles, and therefore releasing less carbon emissions. However, arguments arise whether this kind of New Generation Vehicle is truly clean compared to the existing system, especially in developing country such as Malaysia since current knowledge only focus on Greenhouse Gas (GHG) generation. This study aims on provide better understanding of the environmental consequences of the compact vehicle production activities based on 5 impact classifications which is GHG generation, Acidification, Eutrophication, Carcinogenic Effect, and Human Health measured in "Disability Adjusted Life-Year" (DALY) using Life Cycle Inventory (LCI) Analysis under local electricity mix in 2017 and 2030. A trade-off comparison then can be made to assess the current vehicle technologies with high potential of mass usage in MalaysiaConventional Internal Combustion Engine Vehicle (CV), EV, and HEV vehicles with two types of batteries; Nickel Magnesium Hydride (HEV-NiMH), and Lithium Nickel-Magnesium-Cobalt (HEV-NMC). This study found that EV have slightly higher potential to cause a global warming $\left(5,791 \mathrm{~kg}\right.$ of $\mathrm{CO}_{2}$ equivalent emission), follow by HEV-NiMH $(4,814 \mathrm{~kg})$, HEV-NMC $(4,596 \mathrm{~kg})$ and CV $(4,166 \mathrm{~kg})$ embodied per vehicle. Cradle-to-gate of $\mathrm{CV}$ is better in term of GHG emission and Carcinogenic impact compared to all the studied subjects but in overall measurement, it is not the best solution for human health, measured in DALY. Conversely, HEV have high environmental impact on the same categories. DALY for 2017 EV production is at 0.0014 , CV at 0.0019 , HEV-NiMH at 0.0036 and HEV-NMC at 0.0022 . The situation created a trade-off between having higher Acidification and Eutrophication from CV production against having higher GHG emission of its replacement EV production.
\end{abstract}

Keywords: transportation, passenger car, electric vehicle, lifecycle inventory analysis, environmental risk

\section{Introduction}

\subsection{Background, Purpose \& Present State of Research}

Global anthropogenic carbon dioxide increased alarmingly since the past decade, forecasted to pass 400ppm in 2016 (Betts, Jones, Knight, Keeling, \& Kennedy, 2016) caused from fossil fuel burning such as energy production and vehicle use. This situation will most likely bring catastrophic consequences if no intervention is taken. Hence, increasing environmental awareness and desire to reduce our reliance on fossil fuel give rise to the introduction of Hybrid Electric Vehicle (HEV) and pure battery driven Electric Vehicles (EV) to reduce the impact from the transportation sector. These new generation vehicles tend to have higher fuel efficiency and lower emissions compared to current mass produced conventional internal combustion engine vehicles (CV).

Several countries lead in this New Generation Vehicle production and adoption. Japan for instance is seeing registered New Generation Vehicle exceeding five million units in 2015 (Japan Automobile Manufacturers Association Inc., 2016) which was driven by strong government policy towards clean emission vehicle. Similarly in Norway, EV contributed to 22\% of total vehicle sales in 2015 (Jeff Cobb, 2016). Increasing trend of New Generation Vehicle ownership can be seen across European Union countries due to various EV and HEV friendly policies and incentives(International Energy Agency Organization, 2015). 
Ever since the successful introduction of mass-produced New Generation Vehicles, Toyota and Honda leap far ahead in HEV technology compared to other manufacturers, and Nissan turns out to be the main producer of EV. New technological innovations help Japan to be the global leader of New Generation Vehicle production and export, while having production facilities in foreign nations. In recent years, United States also shown great interest in embracing cleaner emission vehicles. Tesla is starting to dominate the electric cars market. However, arguments arise whether this kind of New Generation Vehicle is truly clean compared to the existing system, especially in developing country such as Malaysia. Out of 11 million active passenger cars here, only 50,000 units is consisting of new generation vehicles (Ministry of Transportation Malaysia, 2015). This trend is unlikely to change as the current policies still favors the previous generation vehicles, further degenerating the environment. Worse, Malaysia ended support for New Generation Vehicle in December 2013 through disposition of tax incentive after only 2 years of application (Monical, 2014). This decision leads to a plummeting number of New Generation Vehicles being sold in the market while reducing public confidence on future of New Generation Vehicle. Changing the situation requires an underlying improvement and comprehension in policy-making. The last improvement in vehicle-environmental related policy was done in 1996. Current vehicle emission regulation, only equals to EURO 2 emission standard while developed world are currently embracing EURO 6, further indicating that a vehicle policy overhaul is long overdue.

One of the strong point of New Generation Vehicle is having much better fuel efficiency compared to conventional vehicles, and therefore having less carbon emissions. However, policy makers continue to dispute whether this kind of New Generation Vehicle is truly clean especially if embodied emissions is being factored in. Several studies have been done in order to study this through life cycle assessment of New Generation Vehicle. Brinkman et al. (2005) uses probability based distribution function to measure the energy use and emission for individual vehicle focusing more on the fuel system variable than vehicle production inventory. Hawkins uses the whole lifecycle of a vehicle as basis of study, including usage, fuel type used, mileage, and based on European condition. Additionally, Hawkins et al. (2013) uses the Eco-Invent database for inventory with ReCiPe for impact calculation method. Higuchi et al. (2012) uses data from existing material from Japanese literature to manually calculate the Disability Adjusted Life Year (DALY) and Expected Increase in Number of Extinct Species (EINES) based on Japanese specific case while Zackrisson et.al (2010) alternatively uses Eco-Invent database as information source to estimate the impact of Lithium Ion Battery for EVs. This database serves as tools in order to quantify the impact of each product being studied.

Another related study is from Messagie et al. (2010) which assess the vehicle technologies based on Belgium inventory context, also using information from Eco-Invent database. Hawkins et al. (2012) also stated that out of 51 LCA studies being reviewed, none of it provides a complete assessment of a single vehicle which may lead to a significant error due to insufficient representation of production phase. Similarly, Nordelöf et al. (2014) presents a conclusion based on 79 research papers of the same area. Main problems are related to intention of study application and proper reason of carrying out the study. Correspondingly, this study aims to answer the question related to quantitative and comparative environmental impact of various type of vehicle production stage. Also, results of this study is expected to provide supporting information for manufacturers and policy makers to improve related environmental management policies especially in national level.

This study aims to quantify the amount of environmental impact of vehicle production activities from material mining until final production of compact passenger vehicle cars in Malaysia using IDEA database and LIME factorization method. This article will provide 5 impact classifications which is Greenhouse Gas (GHG) generation, Acidification, Eutrophication, Carcinogenic Effect, and overall Human Health Impact - DALY. An integration calculation is done via Life-cycle Impact Assessment Method Endpoint Modeling (LIME2) methodology by (Itsubo \& Inaba, 2010) based on the information generated. This method uses material and weight based calculation in order to determine the impact for each product and process. Result of impact calculation carry the purpose as evaluation information between the vehicle technologies. It also serves as calculation basis for modeling of vehicle management policy for the determination of best case scenario to assist policy development of future regulation adaption and environmental improvements.

Study will also be limited on the simulation of production to Malaysia context, with implementation of localized data information. Power generation mix for national grid is used as one of the primary variable with electricity production divided into five major categories; coal, natural gas, hydro, nuclear, and renewables.

\section{Method and Modeling Process}

\subsection{Life Cycle Assessment Method}

The assessment method used to evaluate certain stage of vehicle lifecycle is known as life cycle assessment 
(LCA). It includes all life stage including production, usage and post-usage thus also known as "cradle-to-grave". Each life cycle stage has plenty of variables which have the potential to modify the outcome of lifecycle study. Nearly all studies found focused on vehicle cradle-to-grave analysis. Moreover, in order to create an LCA analysis, researchers often left out the details of material inventories with minor attention given in cradle-to-gate stage. Hence, some study focus only on specific stage of vehicle lifecycle which is known as Life Cycle Inventory (LCI) or "cradle-to-gate". One reason for focusing on limited life stage is to increase the transparency and improving existing understanding and estimation (Hawkins et al., 2013).

Previous LCI study for CV cars ranges from 4500 to $10,000 \mathrm{~kg}$ of $\mathrm{CO}_{2}$ being released during the whole process of production (Gbegbaje-Das, 2013; Maclean \& Lave, 2003; Schweimer, 2000; Volkswagen AG, 2012). Hawkins (2013) offered a factorization of $5 \mathrm{~kg} \mathrm{CO}_{2}$ per $5 \mathrm{~kg}$ of the vehicle weight. Most studies were also found using heavier passenger vehicles compared to this study. Nearly all of the current LCA \& LCI studies utilize inventory database form either GREET from US or Eco-Invent from Europe. Absence of studies utilizing tools from Asia gave idea to this paper.

\subsection{Scope, System Description}

This paper evaluates the risk of environmental impact of all vehicle classes from the viewpoint of Life Cycle Inventory (LCI). Studies of environmental impact of vehicle lifecycle has been done by various researchers focusing on whole vehicle lifecycle (Hawkins et al., 2013; Majeau-Bettez, Hawkins, \& Stromman, 2011). Due to the complexity of Life Cycle Assessments calculations, researchers opted to use commercially available software using many available inventory databases.

This situation had lead this study into constructing own vehicle model in LCA software. It is decided to utilize MiLCA software tool as to provide an alternative analysis compared to other existing articles. Clues for the inventory database had been collected from various existing sources (Althaus, Gauch, \& Empa, 2010; Babu \& Ashok, 2014; Majeau-Bettez et al., 2011). Unlike previous studies, vehicle LCI in this research uses Inventory Database for Environmental Analysis (IDEA database) which was developed and maintained by Japanese Environmental Management Association for Industry. This LCI research focus is exclusively from material extraction from mining activity until the finished product is ready for delivery (cradle-to-gate analysis) without consideration of the usage and end-of life stage. LCI was originally only one part of LCA studies. The reason for focusing on production stage is to provide a clear and unbiased assessment between the technologies.

Environmental assessment used in this study is based on "Lifecycle Impact Assessment Method Based On Endpoint" (LIME and LIME2) methodology. LIME method basically covers the evaluation of common environmental impact such as Global Warming Potential, Acidification Potential (AP), Eutrophication Potential (EP) and Carcinogenic Potential. LIME2 expansion offers to further integrate the inventories in order to provide damage on human health and damage on ecosystem index. The vehicle types being studied is CV, HEV with Nickel-Metal Hydride (Ni-MH) and Nickel Manganese Cobalt Oxide (NMC) based Lithium Ion (Li-Ion) batteries, and EV with NMC Li-ion batteries. It is modelled according to IDEA inventory database which are based from statistical and industry input of Japan.

In order to estimate the associated risk from vehicle production, it is decided to construct a vehicle inventory model from past researches for most components before any analysis can be done. As for base model, we chose to model a Conventional Internal Combustion Engine Vehicle based on a locally manufactured vehicle as the 'glider' - a vehicle with all necessary components and equipment, minus the addition of the vehicle power plant and its immediate components. Furthermore, a modified version of the vehicle is also being modeled with additional parts suited for Hybrid Electric Vehicle and Battery Electric Vehicles. Model build is based on material type and weight for each component. This information is used as input on IDEA database to calculate all the necessary upstream processes involved either directly (foreground) or indirectly (background). Our estimation uses global average values from IDEA database as basis of calculation for this study with modification to suit Malaysian case.

\subsection{Time Period}

The energy mix of 2017 and 2030 was used to test whether the planned energy mix have any substantial difference on overall environmental impact. The Energy Commissions of Malaysia (2013) provided local historical and future plan of electricity generation. The country plans to generate $53 \%$ of electricity from Coal, $41 \%$ from national gas, while $4 \%$ from hydroelectric dam and $2 \%$ from other renewables in 2017 . However, in $2030,52 \%$ of electricity will be generated from coal, $24 \%$ from natural gas, $9 \%$ from the planned nuclear power plant, $13 \%$ from hydroelectric plant and 3\% from other renewable sources. 


\subsection{Target Area}

Aiming at quantifying the impact of vehicle produced in Malaysia, the target area is Malaysia. Boundary for the lifecycle study will be from cradle-to-gate, which starts from prime material extraction until the vehicle is ready to be delivered. Complimenting this is geographic boundaries which limits to Malaysia. Most inventory data for vehicle production and material mining was using the supplied data from IDEA on Malaysia. However, the vehicle model, parts and component weight was modified to reflect the target vehicle models. Malaysian power generation characteristics was also integrated into the modified data.

\subsection{Inventory and Analysis}

This study limits the LCA scope until the production process of a completed compact passenger car. Functional unit for this study will be on per vehicle basis. For the purpose of modeling, logistical part of each inventory were excluded as the main components was considered to be manufactured in-house (foreground). Transportation of inventories further up in the production stream (background) has been integrated within each production steps. The compact vehicle is selected in this model due to the very high ownership of compact cars in Malaysia (Ministry of Transportation Malaysia, 2015).

Table 1. Vehicle model component parameter (in Kilogram weight)

\begin{tabular}{lcccc}
\hline Component modules & $C V$ & $H E V(N i M H)$ & $H E V(L i-I o n)$ & $E V$ \\
\hline Curb weight 980kg & 830 & 830 & 830 & 830 \\
Glider & & & & \\
Internal Engine & 150 & 150 & 150 & - \\
NiMH battery (55.3aH per KG) & - & 28 & - & - \\
Li-Ion battery (112aH per KG) & - & - & 13.8 & 200 \\
Power Distribution Unit & - & 2.9 & 3.9 & 3.9 \\
Inverter & - & 9.5 & 9.5 & 9.5 \\
Electric Motor & - & 26.5 & 26.5 & 42.4 \\
\hline
\end{tabular}

Base vehicle used as model for this study only weighted $980 \mathrm{~kg}$. It was based on one glider shell which consists of all the necessary parts to be distinguished as a complete vehicle which includes all the interior and exterior parts \& panels, tires and its spare, windows, cables and instrument, lead-acid type battery, minus the engine and power generation unit with its auxiliary items. Main difference between vehicle models can be seen in Table 1 . As for Electric motor, the value of $50 \mathrm{~kW}$ for $\mathrm{HEV}$, and $80 \mathrm{~kW}$ for EV was used. Power distribution and inverter remains the same for both units. All foreground inventories for electric motor and its directly related components is gathered from Habermacher (2011).

Previously New Generation Vehicle was often modeled with weight reduction compared to existing vehicles. However, in recent years the manufacturers started to implement the hybridization of current vehicle models without the weight reduction as battery technology continues to shrink in size. Therefore, this study will use the same CV models as basic model and retrofit with respective New Generation Vehicle System.

There are plenty of high capacity batteries deemed suitable for electric vehicle usage. Majeau-Bettez et.al. (2011) provided the inventories for Nickel-Metal Hydride and Li-Ion battery used in this study. Two types of batteries being used in the HEV model - Nickel Magnesium Hydride (NiMH) and Nickel-Manganese-Cobalt Oxide (Li-Ion NMC) which have higher energy density per kilogram compared to NiMH as a comparative assessment. The battery energy capacity for HEV is fixed to $1550 \mathrm{wH}$ and $44000 \mathrm{wH}$ for EV model based on currently available vehicle in the market. The EV being modeled in this study is expected to be able to reach $270 \mathrm{~km}$ per full charge. This travel distance represents the average of one week of commute for residents in Kuala Lumpur for day-to-day activities.

Impact categories being considered for this study in order to quantify the environmental impact of vehicle construction is shown in

Table 2. Global warming potential (GWP) which calculated at per kilogram of carbon dioxide equivalent is commonly used as indicator for climate change. Acidification calculated using LIME represents the potential of 
transforming air and ground in becoming more acidic, which technically including acid rain potential (Itsubo \& Inaba, 2012a). Eutrophication is the potential of causing algae bloom as direct result from increase of nutrient salts such as phosphorus and nitrogen. This have the potential to increase biochemical oxygen demand and causing suffocation of aquatic lives. Carcinogen being measured in LIME target on toxic chemicals which may endanger human health. It is characterized as Human Toxicity Potential (Carcinogen) and being factorized as 1 $\mathrm{kg}$ of benzene equivalent exposure. The values also accompanied with 1 main indicator; DALY.

Table 2. Impact assessment parameter

\begin{tabular}{lcc}
\hline Impact Category & Method & Unit \\
\hline Global Warming Potential & IPCC, 2007 & $\mathrm{kg}^{-\mathrm{CO}_{2} \text { eq. }}$ \\
Acidification & LIME, 2006 & $\mathrm{kg-SO} \mathrm{SO}_{2}$ eq. \\
Eutrophication & LIME, 2006 & $\mathrm{kg}$-phosphate eq. \\
Human Toxicity Potential (Carcinogen) & LIME, 2006 & kg-benzene eq. \\
Human Health & LIME2, 2006 & DALY \\
\hline
\end{tabular}

DALY is the characterization of the ability loss of health due to loss of life expectancy. Murray $(1994,1996)$ developed the groundworks for DALY characterization together with World Health Organization for research on the Global Burden of Disease. Itsubo and Inaba (2012b) modified this in order to compute the impact of each substance used in LCI for LIME2 to make calculation easier. In our case, DALY is being calculated for the passenger car production sector. The damage factors are initially calculated by product inventory's DALY per kg for each substance before integrating all of the substance. This gave the result of total DALY expressed in number of year loss. This is expressed in Equation 1. Substance impact have been pre-calculated in the LCI tool.

DALY Index $_{\text {Year }}=\sum_{\text {Impact Substance }} \sum_{\text {Damage Factor }}{ }^{\text {Impact }}($ Human Health,Substance $) \times$ Inventory $($ Substance $\left.)\right\} \quad$ Equation 1

\section{Result and Discussions}

\subsection{Factorized Environmental Impact}

Evaluation results in Figure 1 to Figure 8 is the LCI comparison between four vehicle technologies in question. It represents current conventional internal combustion engine vehicle (CV), Hybrid electric vehicle with Nickel Metal Hydride (HEV-NiMH) batteries, Hybrid electric vehicles with batteries of Lithium Nickel-Magnesium-Cobalt Oxide type (HEV-NMC) and pure battery driven electric vehicle (EV). It was modelled by power generation mix of Malaysia in 2017 (see Appendix A).

Environmental impact in interest are Global Warming Potential (GWP) measured from greenhouse gas emissions, Acidification, Eutrophication, Carcinogen Emission, and indexed in Disability-Adjusted-Life-Year (DALY). Calculation and factorization was done using LIME2 library and methodology apart from GWP which uses IPCC factoring method.

The global warming potential of passenger vehicle production in Malaysia is shown in Figure 1. The values portrayed is results of factorization based on IPCC 2007 method for each emitted gas. Production of electric cars based on the same platform have the potential to increase $39 \%$ extra $\mathrm{CO}_{2}$ equivalent gas per vehicle. This increase was due to the production of the electrical drive components which contributes $960 \mathrm{~kg}$ of $\mathrm{CO}_{2}$ equivalent GHG whilst the $200 \mathrm{~kg}$ Lithium NMC carries $1860 \mathrm{~kg}$ of GHG. HEV with NiMH battery also releases a noticeable increase of GHG compared to Lithium NMC due to higher mass required to carry the same energy capacity. NiMH batteries carries $\mathrm{CO}_{2}$ intensity of $14.96 \mathrm{~kg} \mathrm{CO}_{2}$ for each $\mathrm{kg}$ as oppose to $13.41 \mathrm{~kg}$ in Lithium NMC. Changing of power generation mix to include nuclear, solar, and more hydroelectric energy as planned is likely to reduce the total GHG by a slight margin. 


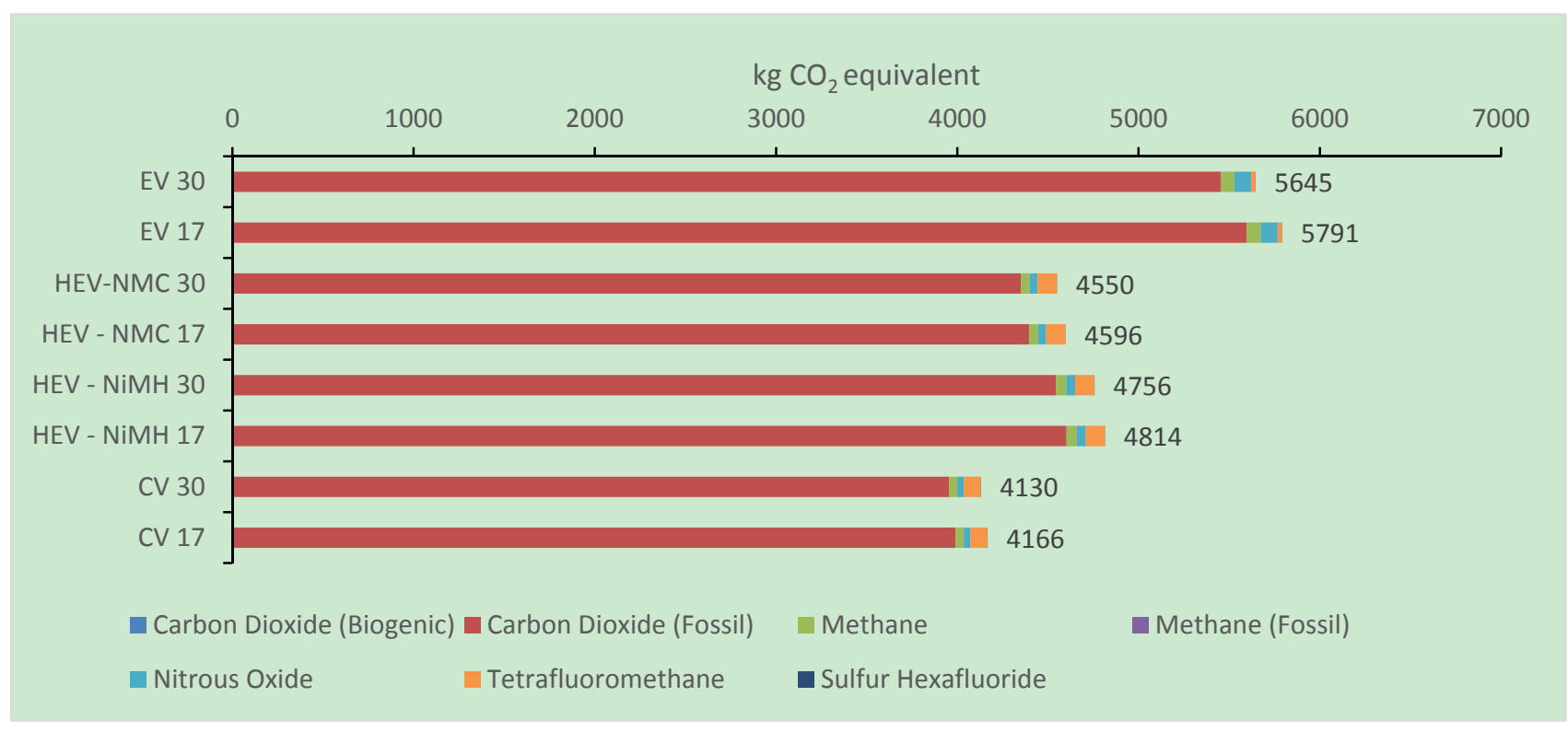

Figure 1. Global Warming Potential of passenger vehicle production in Malaysia, measured in kilogram of CO2 Note: Electric Vehicle (EV), Hybrid Electric Vehicle with Lithium Ion battery (HEV-NMC), Hybrid Electric Vehicle with Nickel Metal Hydride battery (HEV-NiMH), Conventional Internal combustion engine vehicle (CV). $16=$ modelled with 2017 power mix, $30=$ modelled with 2030 power mix.

Global Warming Potential is often used as common measurement for vehicle technology comparison. This provide an opportunity for a comparative analysis with previous studies. Table 3 lists the GHG comparison between result of LCI between previous studies and this study, under vehicle expected lifetime of $150,000 \mathrm{~km}$. GHG emission is lowest compared to other existing studies at 4,166 kg per CV. Reason for this is the compact vehicle model being modeled for the study, as well as inventory data uncertainty caused by different database used, and power generation mix used in vehicle production.

Table 3. Comparative GHG emissions of CV with other studies

\begin{tabular}{lcc}
\hline Impact Category & Total GHG Emission $(\mathrm{kg})$ & GHG emission per distance $(\mathrm{g} / \mathrm{km})$ \\
\hline This Study & 4,166 & 27.77 \\
(Schweimer, 2000) & 4,402 & 29.35 \\
(Maclean \& Lave, 2003) & 10,000 & 66.67 \\
(Notter et al., 2010) & 6,000 & 40.00 \\
(Dunn, Gaines, Kelly, James, \& Gallagher, 2015) & 7,000 & 46.67 \\
(Volkswagen AG, 2012) & 5,000 & 33.33 \\
(Hawkins et al., 2012) & 6,450 & 43.00 \\
\hline
\end{tabular}

Cradle-to-gate GWP studies for Battery Electric Vehicles, done by Del Duce et al. (2014) suggested $74.6 \mathrm{~g} / \mathrm{km}$ while Hawkins et al. (2013) suggests 87 to $95 \mathrm{~g} / \mathrm{km}$ and Onat et al. (2015) $43.83 \mathrm{~g} / \mathrm{km}$ for $150,000 \mathrm{~km}$ estimated life. Other finding also suggested (Argonne National Laboratory (ANL), 2015; Dunn et al., 2015; Kim et al., 2016; Notter et al., 2010) $66 \mathrm{~g}$ to $70 \mathrm{~g} / \mathrm{km}$ on the same estimated vehicle life. Comparatively, this study only calculated $38.6 \mathrm{~g} / \mathrm{km}$ for the same case. This might be due to the different Lithium Ion battery technology being applied in the model, or different process input being used. The lower output from utilizing IDEA database can provide an alternate understanding regarding environmental emissions.

The human toxicity potential of passenger vehicle production in Malaysia is shown in Figure 2. Production of EV have the highest potential of carcinogenic material emission with each of electric cars emitted about $1.27 \mathrm{~kg}$ 
of benzene equivalent throughout its supply chain under 2017 energy profile. However, changing to 2030 energy profile does not yield any change as we have hoped for. LIME calculated the emissions by integrating all chemicals involved according to its weight emission and later factoring it to equals to a kilogram of benzene. Under this analysis, CV have much less potential for toxicity compared to both HEV and EV.

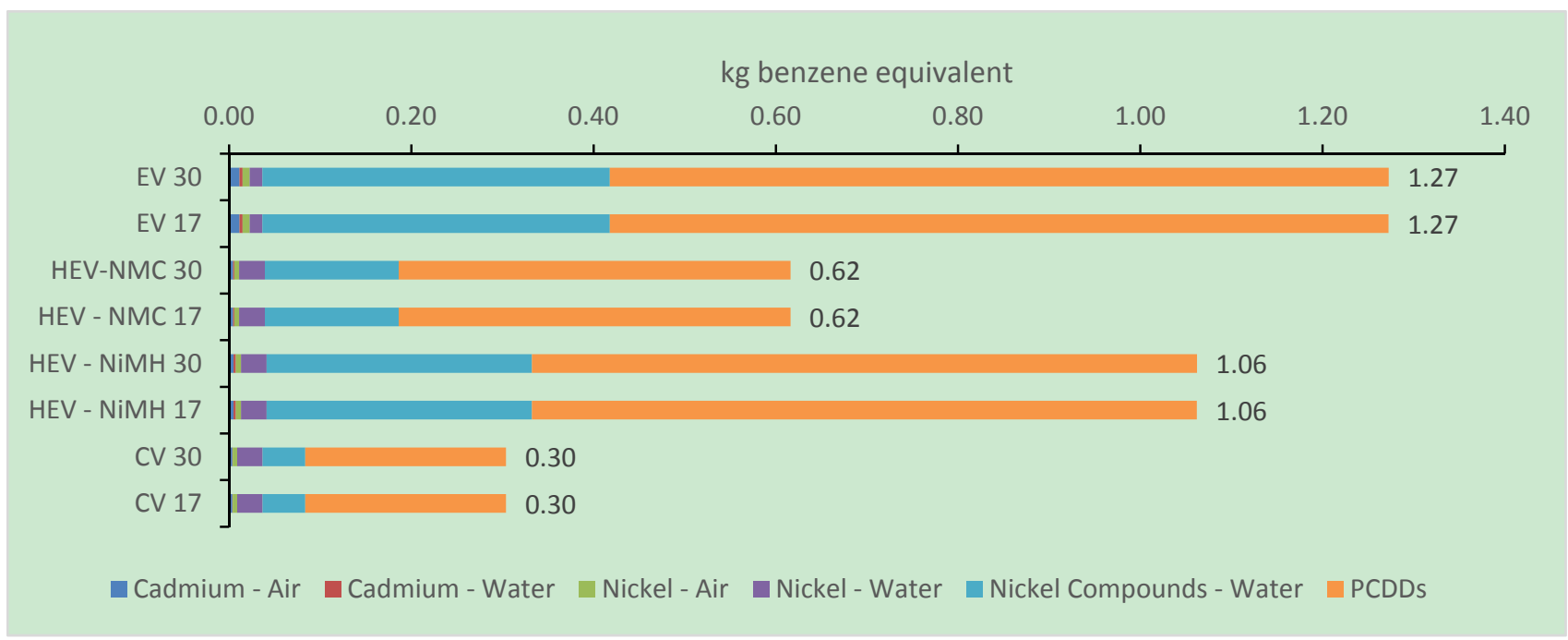

Figure 2. Human Toxicity Potential of passenger vehicle production in Malaysia

However, the same situation is not applicable to Acidification Potential (AP), which is factorized in $\mathrm{kg} \mathrm{SO}_{2}$ equivalent. LCI under IDEA database shown that highest potential of producing acid rain is generated from production of HEV with NiMH batteries as shown in Figure 3. The lowest score was EV production which was likely due to reduced utilization of copper and sulphuric acid during smelting of mineral ores (aluminium, copper, zinc, lead, and iron) for the engines. This is consistent with results from Boureima et al. (2012). This is not always the case nevertheless when compared to another related study by Hawkins et al. (2013) which indicates higher AP of $10 \%$ compared to base model. Highest emissions are from release of nitrogen dioxide as a by-product from electric power generation. In another sense, EV have lower Acidification potential, but resulted in higher $\mathrm{CO}_{2}$ emission during production. This created trade-off between AP and HTP, as well as AP and GWP.

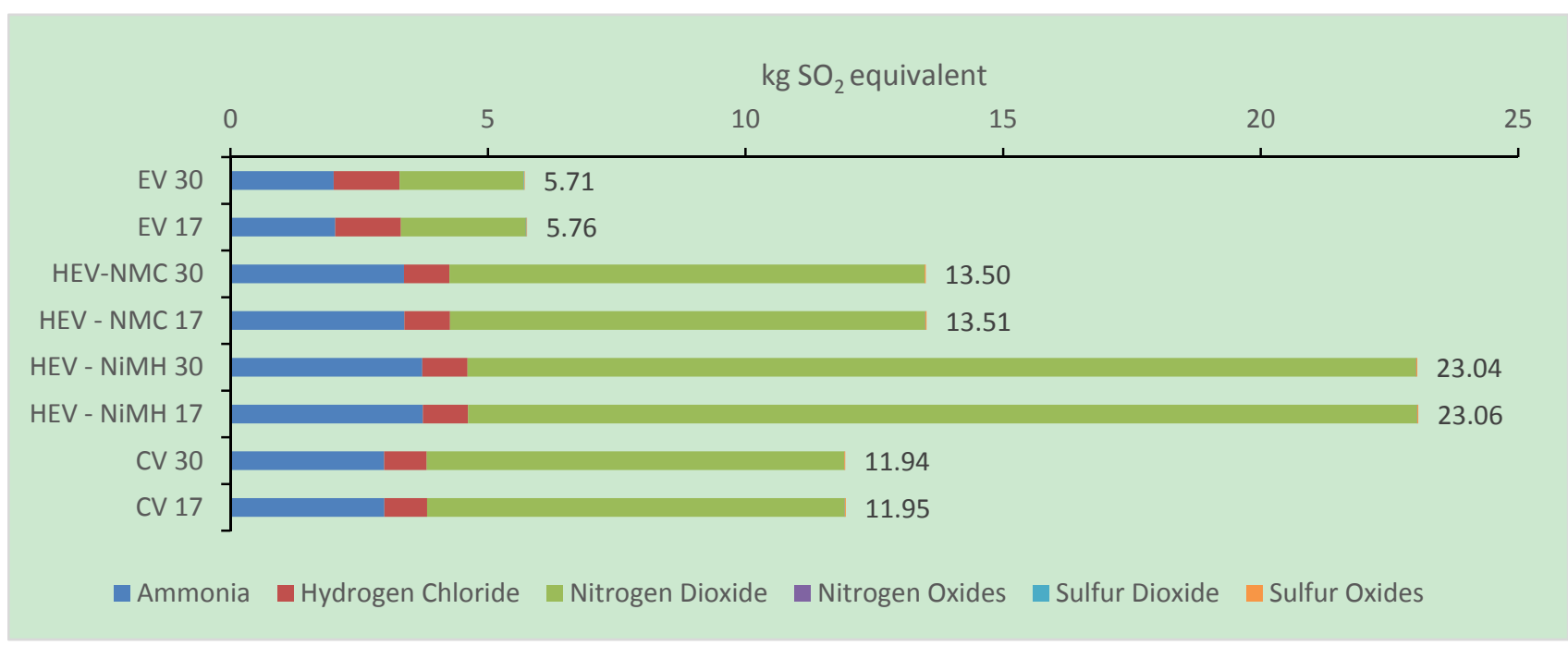

Figure 3. Factorized Acidification Potential for different type of passenger vehicle production in Malaysia

Similarly, Eutrophication Potential for EV is lowest among the vehicles while HEV with NiMH batteries have nearly four times the amount of phosphate equivalent emission compared to CV as shown in Figure 4. This 
increase of eutrophication potential is caused by increased use of nickel and copper in its batteries and electronic motor.

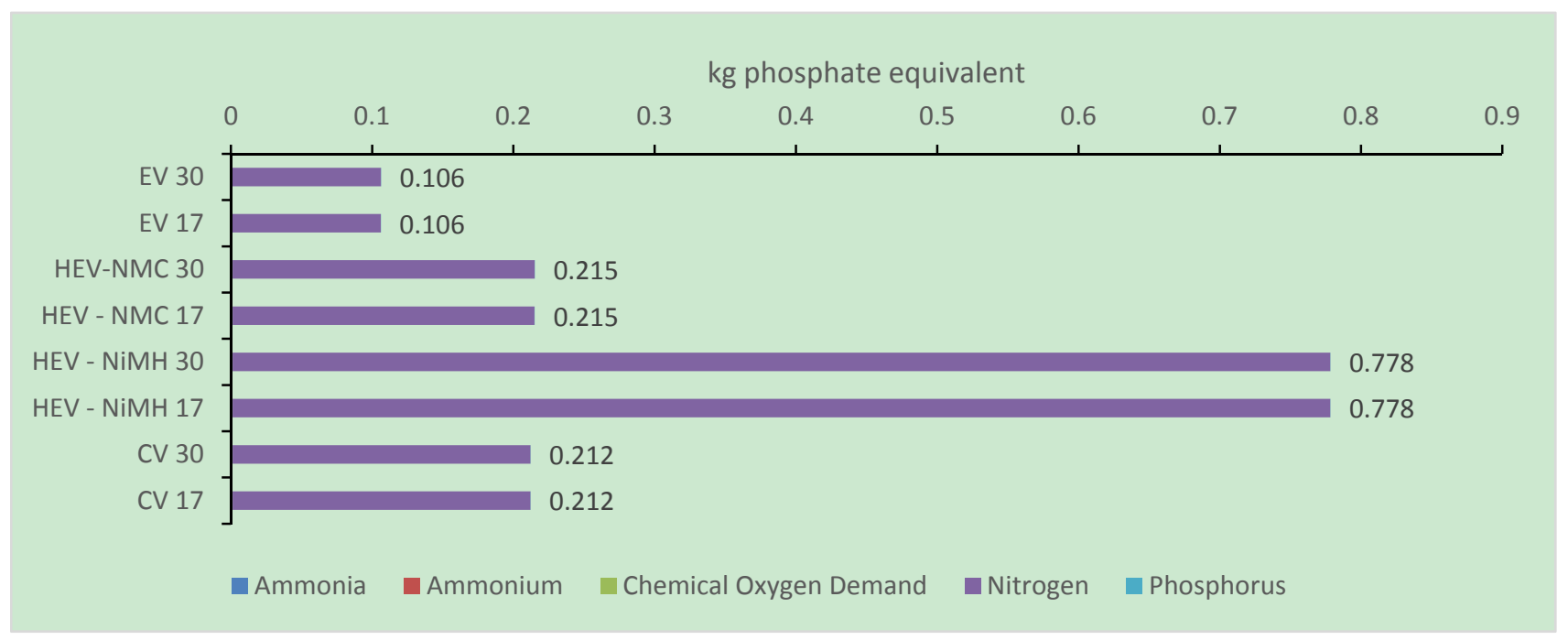

Figure 4. Factorized Eutrophication Potential for different type of passenger vehicle production in Malaysia

Previous studies such as listed in Table 3 focus primarily on the impact of GHG from vehicle production. This creates a situation where production of EV seems to have worse environmental impact compared to CV. DALY is often used as quantitative measurement of overall impact on human health endpoints. It is expressed as the number of years lost due to ill-health, disability or early death. Table 4 list the factorized DALY related materials used throughout the process of vehicle production for CV, both HEV, and EV. Factorize DALY on NiMH equipped HEV is highest at 0.0036 represented from the essential elementary flow while NMC equipped HEV scores 0.0022 DALYs. This is followed with CV and EV at 0.0019 and 0.0014 respectively.

LCI analysis found that highest DALY impact is brought by key GWP components methane and carbon dioxide. However, cumulative impact from non-GHG related have the potential to change the total DALY of each vehicle. Further analysis shown that majority of the damage is from production of engine and car shell. HEV with NiMH batteries scored the most regardless of the two application of energy mix. On top of having an engine, it also equipped with $28 \mathrm{~kg}$ of NiMH batteries which contributes $32 \%$ of total HEV production DALY. 
Table 4. Factorized DALY impact for each vehicle type with its respective material based on 2017 and 2030 power generation

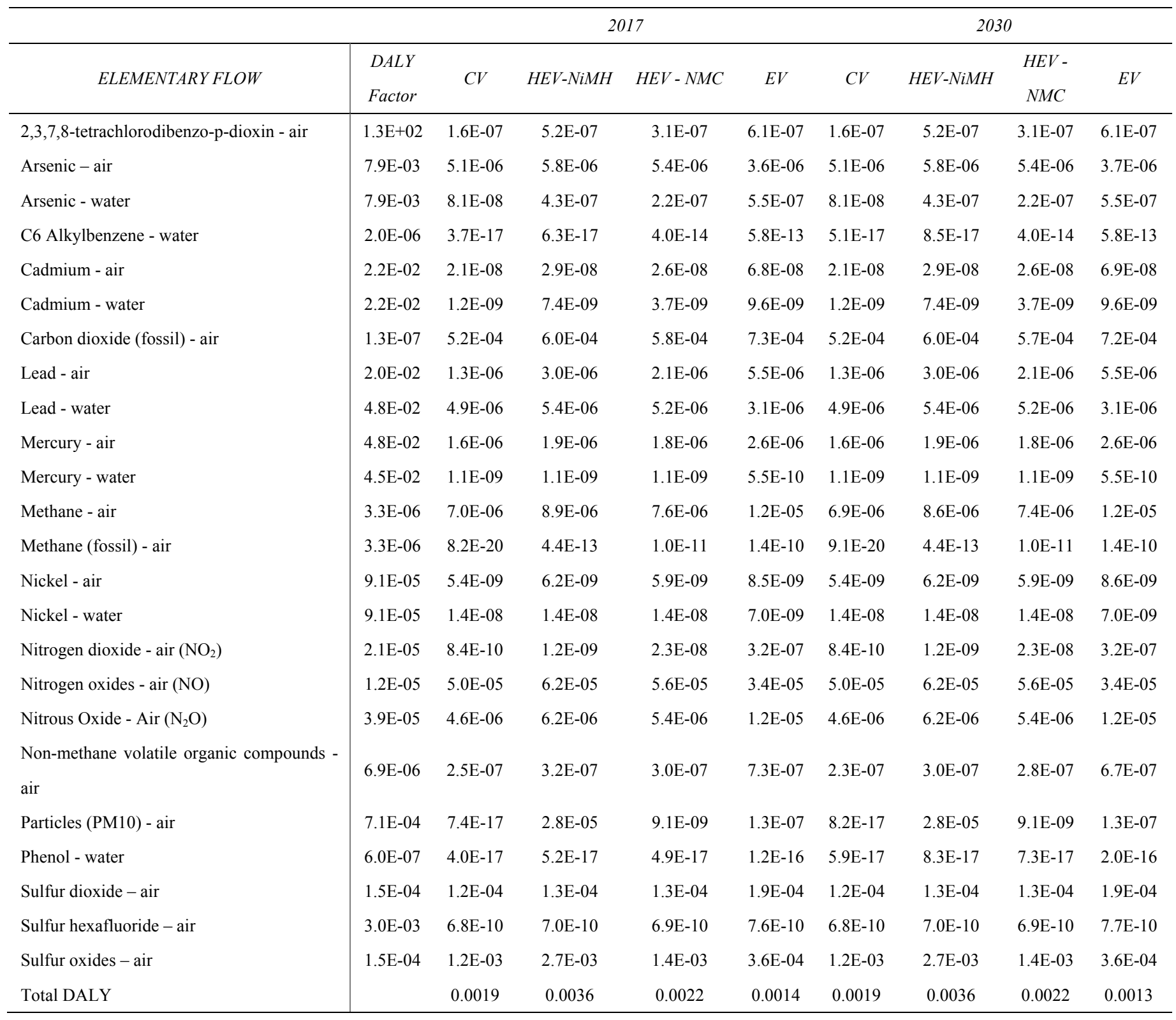

Absence of an engine which requires casting process and constant melting of metal enables cradle-to-gate of an $\mathrm{EV}$ to be reduced over half total DALY as opposed to current CV. An engine block is the largest single piece of metal in a car, housing components such as pistons and cylinders. It need to be casted from molten metal in order to retain its strength and heat resistance. This process utilizes most of the energy for CV and HEV production. This situation overturns the disadvantage for EV in the initial assessment. Consistent with other impact assessment, the 2030 power mix does not carry any substantial difference for each vehicle's DALY.

National vehicle fleet transformation from $\mathrm{CV}$ to $\mathrm{EV}$ will also create trade-off especially between GHG generation as specific impact, against overall human health impact which was depicted in Figure 5. As the production of EV increases, so will total GHG emission from higher EV potential. On the other hand, overall Human Health will be reduced creating a trade-off. Current policy analysis method relies heavily only on GHG emissions while giving less care on the overall impact. This shows that producers, policy makers and governmental agencies need to thread more carefully in order to take measure to control the environmental impact by the transportation sector. 


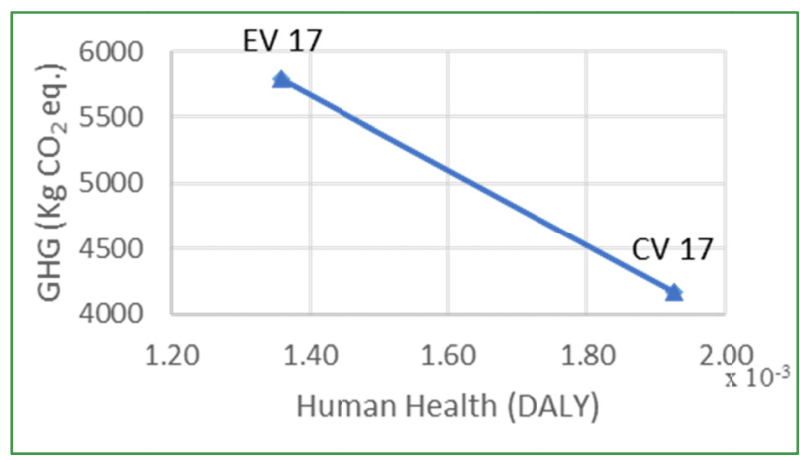

Figure 5. Fleet transformation trade-off between Conventional Vehicle (CV) and Electric Vehicle (EV)

Environmental impact from vehicle production also have the potential to be reduced. This can be achievable through weight reduction, as well as introduction of newer production processes. Moreover, less impact can also be gained by using renewable energy in much larger scale such as demonstrated in the result between 2017 and 2030. Emission reduction is a direct result from the increase of renewable energy from $2 \%$ to $2.6 \%$ and increase of hydroelectric energy production from $4.3 \%$ to $12.6 \%$.

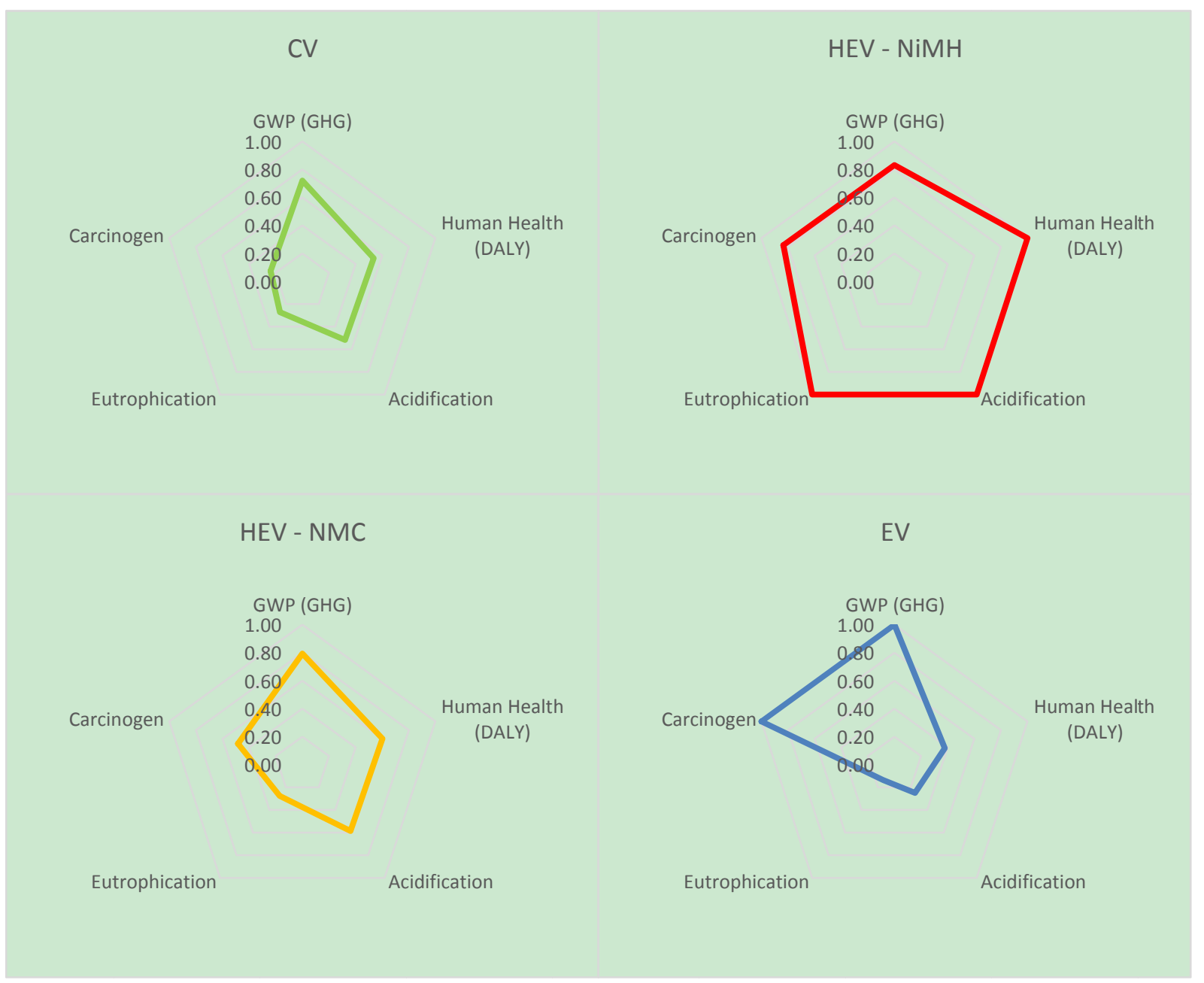

Figure 6. Factorized compact vehicle production environmental impact

Summary of environmental impact from compact passenger vehicle is depicted in Figure 6. HEV-NIMH is shown to have the largest impact in all the impact category studied. However, newer battery technology such as lithium ion on HEV NMC have managed to reduce this impact substantially making fleet transformation towards 
this technology needs to also weight the impact of vehicle usage, fuel consumption, and distance travelled. Trade-off of vehicle transitions to EV can also be observed here.

\section{Conclusions}

Present work is an expansion of LIME2 methodology into the assessment of compact vehicle production in Malaysia. The environmental impact of compact passenger vehicle based on 5 impact classifications; Greenhouse Gas (GHG) generation, Acidification, Eutrophication, Carcinogenic Effect, and Disability-Adjusted-Life-in-Year (DALY) covering only until vehicle production phase. Vehicle models is inventoried by using IDEA inventory database, and analysed using LIME2 method. Main methods for the integration of environmental impacts is better represented with impact data from Asian countries under LIME2 method, especially in term of population body weight and size. Thus, its use is more suitable for Malaysia use.

This study examines three types of compact passenger vehicle production in Malaysia which are Conventional Internal Combustion Engine Vehicle (CV), Battery Electric Vehicle (EV), and Hybrid Electric (HEV) vehicles with two types of batteries; Nickel Magnesium Hydride (HEV-NiMH), and Lithium Nickel-Magnesium-Cobalt (HEV-NMC).

Main conclusion from this study is as follow;

First, production of EV have slightly high potential to cause a global warming, follow by HEV and CV. Even without the traditional components, EV consumes higher energy for the production of the $200 \mathrm{~kg}$ battery and its components. The $5,791 \mathrm{~kg}$ embodied $\mathrm{CO}_{2}$ emissions is $39 \%$ increase compared to the existing $\mathrm{CV}$. The values generated in this study are significantly low compared to other existing studies mainly due to reduction of the total vehicle weight. Overall impact, DALY is much lower compared to other vehicle being analysed.

Second, HEV-NiMH production release 4,814 $\mathrm{kg} \mathrm{CO}_{2}$ while HEV-NMC production emitted 4,596 $\mathrm{kg} \mathrm{CO}_{2}$ during its production process. HEV-NiMH also have highest acidification potential at $23.06 \mathrm{~kg} \mathrm{SO}_{2}$ and eutrophication potential at $0.78 \mathrm{~kg}$ phosphate equivalent for each unit production. Utilization of this two different battery technologies have notable difference especially in Carcinogen, Eutrophication, and Acidification impact categories. Swapping the NiMH batteries to lithium ion batteries can provide less impact to the environment.

Third, cradle-to-gate of $\mathrm{CV}$ is better in term of GHG emission and Carcinogenic impact compared to all the studied subjects. CV production process added $4,166 \mathrm{~kg}$ of GHG and $0.30 \mathrm{~kg}$ of benzene equivalent into the environment for every unit produced, posing the least impact among all the vehicles being studied. However, if vehicle usage emission is being considered, the total emissions from $\mathrm{CV}$ will become the worst as it consumes much more fuel, and thus produces more exhaust by-products compared to the other vehicle type.

Lastly, the various impact is being summarized in term of DALY. Although GHG emissions from EV is the highest during production, the overall index in human health is the least among the vehicles being studied. Lowest DALY from production is exhibited by EV at 0.0014 , followed by CV at 0.0019 , HEV-NMC at 0.0022 and finally by HEV-NIMH at 0.0036 . This shows that EV production still is the best solution for the global sustainability. Under this premise, national car manufacturers should invest more on creation and production of EVs, while governing bodies should develop more active policies towards increasing the ownership of Electric Vehicles.

This study also provided the trade-off between GHG and DALY in vehicle fleet transition from CV to EV. Although GHG emission from EV is higher, overall impact towards human health is effectively $35 \%$ lower compared to conventional vehicles production.

Moreover, as EV technology is considerably new, the improvement potential is much more compared to conventional vehicles. Current state-of-knowledge regarding fuel consumption HEV and EV also have the capability to reduce the overall vehicle lifecycle impact much lower compared to CV. Upcoming battery improvement may have the potential to reduce it further down and helps to create a more sustainable future.

\section{Acknowledgement}

Special thanks for Dr. Naoya Kojima and Dr. Mianqiang Xue for providing invaluable input towards completion of this study. The authors would also like to thank Majlis Amanah Rakyat (MARA Malaysia) for providing financial support for this project. The funder has neither conflict of interest nor any influence over any stage of this manuscript production.

\section{References}

Althaus, H.-J., Gauch, M., \& Empa. (2010). Comparative Life Cycle Assessment in Mobility (in Germany). Dübendorf. 
https://www.empa.ch/documents/56122/458579/LCA-Mobilitaetsvergleich_Bericht.pdf/824aec56-3393-439 e-8bc9-d1a365041e4d

Argonne National Laboratory (ANL). (2015). GREET Model. Tranportation Research and Analysis Computing Center. Illenois: Argonne National Laboratory.

Babu, A., \& Ashok, S. (2014). A novel index for batteries in Hybrid Electric Vehicles. 2014 Power and Energy Systems Conference: Towards Sustainable Energy, PESTSE 2014, (Pestse), 0-4. http://doi.org/10.1109/PESTSE.2014.6805313

Betts, R. A., Jones, C. D., Knight, J. R., Keeling, R. F., \& Kennedy, J. J. (2016). El Nino and a record CO2 rise. Nature Clim. Change, advance on. Retrieved from http://dx.doi.org/10.1038/nclimate3063

Boureima, F., Messagie, M., Sergeant, N., Matheys, J., Mierlo, J. Van, Vos, M. De, ... Macharis, \& C. (2012). Environmental Assessment Of Different Vehicle Technologies And Fuels. Urban Transport, 128, 12. Retrieved from http://www.witpress.com/elibrary/wit-transactions-on-the-built-environment/128/23204

Brinkman, N., Wang, M., Weber, T., \& Darlington, T. (2005). Advanced Fuel / Vehicle Systems - A North American Study of Energy Use, Greenhouse Gas Emissions, and Criteria Pollutant Emissions, (May). Retrieved from http://www.transportation.anl.gov/pdfs/TA/339.pdf

Del Duce, A., Gauch, M., \& Althaus, H.-J. (2014). Electric passenger car transport and passenger car life cycle inventories in Eco-Invent version 3. The International Journal of Life Cycle Assessment, 1-13. http://doi.org/10.1007/s11367-014-0792-4

Dunn, J. B., Gaines, L., Kelly, J. C., James, C., \& Gallagher, K. G. (2015). The significance of Li-ion batteries in electric vehicle life-cycle energy and emissions and recycling's role in its reduction. Energy Environ. Sci., 8(1), 158-168. http://doi.org/10.1039/C4EE03029J

Energy Commission. (2015). Malaysia Energy Statistics Handbook 2015. Putrajaya, Malaysia.

Gbegbaje-Das, E. (2013). Life Cycle CO2 e Assessment of Low Carbon Cars 2020 - 2030. Victoria. Retrieved from https://trid.trb.org/view.aspx?id=1259326

Habermacher, F., Hellwag, S., Saner, D., \& Althaus, H.-J. (2011). Modeling Material Inventories and Environmental Impacts of Electric Passenger Cars - Comparison of LCA results between electric and conventional vehicle scenarios. Dep. of Environmental Sciences. ETH Zurich.

Hawkins, T. R., Gausen, O. M., \& Strømman, A. H. (2012). Environmental impacts of hybrid and electric vehicles-a review. International Journal of Life Cycle Assessment, 17(8), 997-1014. http://doi.org/10.1007/s11367-012-0440-9

Hawkins, T. R., Singh, B., Majeau-Bettez, G., \& Strømman, A. H. (2013). Comparative Environmental Life Cycle Assessment of Conventional and Electric Vehicles. Journal of Industrial Ecology, 17(1), 53-64. http://doi.org/10.1111/j.1530-9290.2012.00532.x

Higuchi, Y., Wada, N., Nakakubo, T., \& Tokai, A. (2012). Scenario Analysis on the Impact of Diffusion of Next Generation Vehicles on Material Consumption and GHG Emissions. In M. Matsumoto, Y. Umeda, K. Masui, \& S. Fukushige (Eds.), Design for Innovative Value Towards a Sustainable Society (pp. 598-603). Springer Netherlands. http://doi.org/10.1007/978-94-007-3010-6_115

International Energy Agency Organization. (2015). Global EV Outlook 2015. Retrieved May 15, 2016, from http://www.iea.org/evi/Global-EV-Outlook-2015-Update_1page.pdf

Itsubo, N., \& Inaba, A. (2010). LIME 2 : Life-cycle Impact Assessment Method based on Endpoint modeling. (in Japanese). Tokyo: Japan Environmental Management Association for Industry (JEMAI).

Itsubo, N., \& Inaba, A. (2012a). Chapter 0 : Introduction. In LIME2 Life-cycle Impact assessment Method based on Endpoint modeling.

Itsubo, N., \& Inaba, A. (2012b). Chapter 1 : Outline. In LIME2 Life-cycle Impact assessment Method based on Endpoint modeling.

Japan Automobile Manufacturers Association Inc. (2016). 2016 REPORT ON ENVIRONMENTAL PROTECTION EFFORTS Promoting Sustainability in Road Transport in Japan. Tokyo, Japan. Retrieved from http://www.jama-english.jp/publications/env_prot_report_2016.pdf

Jeff Cobb. (2016). Top Six Plug-in Vehicle Adopting Countries - 2015. Retrieved June 1, 2016, from http://www.hybridcars.com/top-six-plug-in-vehicle-adopting-countries-2015/ 
Kim, H. C., Wallington, T. J., Arsenault, R., Bae, C., Ahn, S., \& Lee, J. (2016). Cradle-to-Gate Emissions from a Commercial Electric Vehicle Li-Ion Battery: A Comparative Analysis. http://doi.org/10.1021/acs.est.6b00830

Maclean, H. L., \& Lave, L. B. (2003). Life Cycle Assessment of Automobile/Fuel Options. Environmental Science Technology, 37, 5445-5452. http://doi.org/10.1021/es034574q

Majeau-Bettez, G., Hawkins, T. R., \& Stromman, A. H. (2011). Life Cycle Environmental Assessment of Li-Ion and Nickel Metal Hydride Batteries for Plug-in Hybrid and Battery Electric Vehicles. Supporting Information. Zhurnal Eksperimental'noi I Teoreticheskoi Fiziki, 1-51. http://doi.org/10.1021/es103607c

Messagie, M., Boureima, F., Matheys, J., Sergeant, N., Turcksin, L., Macharis, C., \& Van Mierlo, J. (2010). Life Cycle Assessment of conventional and alternative small passenger vehicles in Belgium. 2010 IEEE Vehicle Power and Propulsion Conference, 32(0), 1-5. http://doi.org/10.1109/VPPC.2010.5729233

Ministry of Energy Green Technology and Water. (2013). KeTTHA Annual Report 2013.

Ministry of Transportation Malaysia. (2015). Transport Statistics 2000-2014 (Report Compilation). Putrajaya.

Monical, C. S. (2014). Hybrid car prices soared (in Malay). Retrieved August 12, 2016, from http://www.sinarharian.com.my/harga-kereta-hibrid-naik-tinggi-1.243001

Murray, C. J. (1994). Quantifying the burden of disease: the technical basis for disability-adjusted life years. Bulletin of the World Health Organization, 72(3), 429-445. Retrieved from http://www.ncbi.nlm.nih.gov/pmc/articles/PMC2486718/

Murray, C. J. L., \& Lopez, A. D. (1996). The global burden of disease: a comprehensive assessment of mortality and disability from deceases, injuries and risk factors in 1990 and projected to 2010. Harvard University Press, 1, 1-35. http://doi.org/10.1186/1471-2458-13-863

Nordelöf, A., Messagie, M., Tillman, A.-M., Ljunggren Söderman, M., \& Van Mierlo, J. (2014). Environmental impacts of hybrid, plug-in hybrid, and battery electric vehicles-what can we learn from life cycle assessment? The International Journal of Life Cycle Assessment, 19(11), 1866-1890. http://doi.org/10.1007/s11367-014-0788-0

Notter, D. A., Gauch, M., Widmer, R., W??ger, P., Stamp, A., Zah, R., \& Althaus, H. J. (2010). Contribution of Li-ion batteries to the environmental impact of electric vehicles. Environmental Science and Technology, 44(17), 6550-6556. http://doi.org/10.1021/es903729a

Onat, N. C., Kucukvar, M., \& Tatari, O. (2015). Conventional, hybrid, plug-in hybrid or electric vehicles? State-based comparative carbon and energy footprint analysis in the United States. Applied Energy, 150, 36-49. http://doi.org/10.1016/j.apenergy.2015.04.001

Schweimer, G. (2000). Life cycle inventory for the Golf A4. Environment and Research, 1-40. Retrieved from http://www.volkswagenag.com/vwag/vwcorp/info_center/en/publications/2007/01/Golf_A4_Life_Cycle_I nventory.-bin.acq/qual-BinaryStorageItem.Single.File/golfa4_english.pdf

Volkswagen AG. (2012). The Life Cycle of a Car - Environmental Commendations Document Progress. Wolfsburg, Germany. Retrieved from http://www.volkswagenag.com/content/vwcorp/info_center/en/publications/2012/07/The_Life_Cycle_of_a_ Car.bin.html/binarystorageitem/file/vw_basisbrochure_gb(1).pdf

Zackrisson, M., Avellán, L., \& Orlenius, J. (2010). Life cycle assessment of lithium-ion batteries for plug-in hybrid electric vehicles - Critical issues. Journal of Cleaner Production, 18(15), 1519-1529. http://doi.org/10.1016/j.jclepro.2010.06.004

\section{Appendix A}

Malaysia Energy Generation Plan 2017 and 2040.

\begin{tabular}{llllll}
\hline Year & $\begin{array}{l}\text { Coal } \\
(\%)\end{array}$ & $\begin{array}{l}\text { Natural Gas } \\
(\%)\end{array}$ & $\begin{array}{l}\text { Hydro } \\
(\%)\end{array}$ & $\begin{array}{l}\text { Nuclear } \\
(\%)\end{array}$ & $\begin{array}{l}\text { Renewables } \\
(\%)\end{array}$ \\
\hline 2017 & 52.8 & 40.9 & 4.3 & 0 & 2 \\
2030 & 52.3 & 23.5 & 12.6 & 8.9 & 2.6 \\
\hline
\end{tabular}

Source: Malaysia Energy Statistics Handbook (Energy Commission, 2015). 


\section{Appendix B}

\section{Ammonia Ammonium Chemical Oxygen Demand Nitrogen Phosphorus}

Figure 4.

\begin{tabular}{|c|c|c|c|c|c|}
\hline GWP (GHG, $\mathrm{kg} \mathrm{CO} \mathrm{C}_{2}$ equivalent $)$ & Factorization & $C V$ & $H E V-N i M H$ & $H E V-N M C$ & $E V$ \\
\hline Carbon Dioxide (Biogenic) & 0 & 0 & 0 & 0 & 0 \\
\hline Carbon Dioxide (Fossil) & 1 & 3994 & 4608 & 4402 & 5609 \\
\hline Methane & 21 & 44 & 56 & 48 & 76 \\
\hline Methane (Fossil) & 21 & 0 & 0 & 0 & 0 \\
\hline Nitrous Oxide & 310 & 38 & 50 & 44 & 97 \\
\hline Tetrafluoromethane & 6500 & 94 & 106 & 107 & 24 \\
\hline Sulfur Hexafluoride & 23900 & 0 & 0 & 0 & 0 \\
\hline Total GWP & & 4170 & 4820 & 4601 & 5806 \\
\hline ACIDIFICATION ( $\mathrm{kg} \mathrm{SO} \mathrm{S}_{2}$ Equivalent) & & $\mathrm{CV}$ & HEV-NiMH & HEV - NMC & EV \\
\hline Ammonia & 5.99 & 0.02 & 0.02 & 0.02 & 0.01 \\
\hline Hydrogen Chloride & 2.61 & 0.00 & 0.00 & 0.00 & 0.00 \\
\hline Nitrogen Dioxide & 0.72 & 0.00 & 0.00 & 0.00 & 0.01 \\
\hline Nitrogen Oxides & 0.72 & 2.99 & 3.74 & 3.38 & 2.05 \\
\hline Sulfur Dioxide & 1.00 & 0.83 & 0.88 & 0.88 & 1.28 \\
\hline Sulfur Oxides & 1.00 & 8.11 & 18.42 & 9.23 & 2.43 \\
\hline Total Acidification & & 11.95 & 23.06 & 13.52 & 5.77 \\
\hline EUTROPHICATION (kg Phosphorus Eq.) & & ICEV & HEV-NiMH & HEV - NMC & EV \\
\hline Ammonia & 0.09 & 0.00 & 0.00 & 0.00 & 0.00 \\
\hline Ammonium & 0.20 & 0.00 & 0.00 & 0.00 & 0.00 \\
\hline Chemical Oxygen Demand & 0.00 & 0.00 & 0.00 & 0.00 & 0.00 \\
\hline Nitrogen & 0.01 & 0.21 & 0.78 & 0.21 & 0.11 \\
\hline Phosphorus & 1.00 & 0.00 & 0.00 & 0.00 & 0.00 \\
\hline Total Eutrophication & & 0.21 & 0.78 & 0.22 & 0.11 \\
\hline \multicolumn{2}{|l|}{ CARCINOGEN (kg Benzene Eq.) } & ICEV & HEV-NiMH & HEV - NMC & EV \\
\hline Cadmium - Air & 3764 & 0.00 & 0.01 & 0.00 & 0.01 \\
\hline Cadmium - Water & 7500 & 0.00 & 0.00 & 0.00 & 0.00 \\
\hline Nickel - Air & 84 & 0.01 & 0.01 & 0.01 & 0.01 \\
\hline Nickel-Water & 182 & 0.03 & 0.03 & 0.03 & 0.01 \\
\hline Nickel Compounds - Water & 8114 & 0.05 & 0.29 & 0.15 & 0.38 \\
\hline PCDDs & 185555963 & 0.22 & 0.73 & 0.43 & 0.85 \\
\hline Total Carcinogen & & 0.30 & 1.06 & 0.62 & 1.27 \\
\hline
\end{tabular}

\section{Copyrights}

Copyright for this article is retained by the author(s), with first publication rights granted to the journal.

This is an open-access article distributed under the terms and conditions of the Creative Commons Attribution license (http://creativecommons.org/licenses/by/4.0/). 